growing. And there is still no way to change media under the microscope and maintain sterile conditions, he says. Nonetheless, Tsai and his colleagues have been able to keep brain slices alive for more than a week, after which time bacteria have started to grow.

Conditions also need to be tightly controlled to minimize artefacts and experiment-ruining variability. Over the run of a protracted experiment, subtle differences in culture conditions can start to look like cell behaviour, notes Alfred Bahnson, a biologist at Kairos Instruments in Pittsburgh, Pennsylvania, which manufactures optically accessible environmental chambers and other long-term imaging products. Movement that appears to be cell migration, says Bahnson, might instead be cells moving downhill or following slight temperature gradients.

\section{Coordinating accessories}

Those imaging issues are typical, says Keith Bogdon, an adviser with consulting company Coalesce Corporation in Larkspur, California, who has researched live-cell imaging products. Often features to control temperature or $\mathrm{pH}$ conflict with features for positioning or focusing cells in the microscope, particularly if researchers want to compare several experimental conditions. "There are a lot of wires and tubes coming out of the plates," says Bogdon, and it is difficult to design a chamber so that cells can be both monitored and unperturbed.

Even after the microscope, environmental chamber, and other equipment are brought together so that cells stay alive, the length of

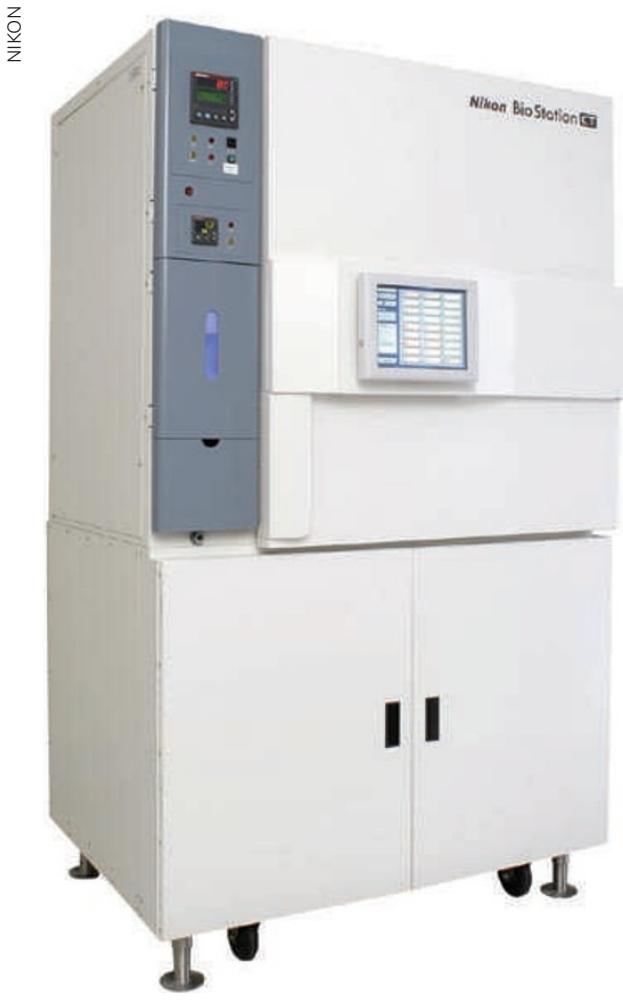

Nikon BioStation CT has software and robotics to allow several scientists to conduct experiments.
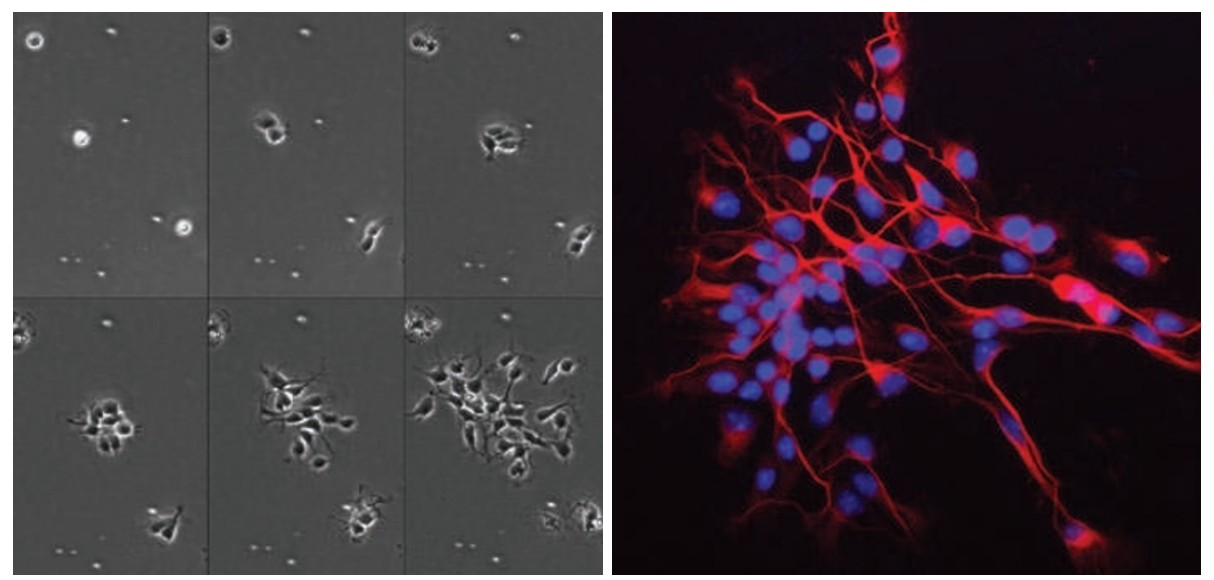

Stills from a film of an individual cell dividing into dozens of neurons (left), and many neural cells produced from a single neural stem cell (right).

experiments can still be a problem. Most labs and core facilities aren't designed to accommodate experiments that tie up equipment for weeks at a time. If a researcher works out too late that some parameters need to be tweaked, it could take months to book the necessary time with the microscope again.

And long-term imaging is costly in money as well as time. Renting equipment from a core facility at, say, US\$20 an hour, 24 hours a day for a week or more could make even a single experiment pricey. "If you do this for half a year," says Schroeder, "you've paid more for renting than for buying." But buying equipment with a six-figure price tag is not always easy. "It's a classic chicken and egg scenario," says Bogdon. "How can researchers get into the area if they don't have the clout to justify funding?"

Still, researchers report that commercial offerings in software, cell incubation, and visual systems have expanded greatly. Microscope systems used for live-cell imaging for time periods of more than 24 hours are produced by companies including BD Biosciences in San Jose, California; Essen BioSciences in Ann Arbor, Michgian; GE Healthcare in Waukesha, Wisconsin; Leica in Wetzlar, Germany; Molecular Devices in Sunnyvale, California; Nikon in Melville, New York; Olympus in Center Valley, Pennsylvania; PerkinElmer in Waltham, Massachussetts; and Zeiss. Each system comes with its own proprietary software and storage options, and additional software is available, all of which tends to require considerable expertise (see 'A software spot').

Molecular Devices offers MetaMorph imaging analysis software; the imaging-processing software MatLab from MathWorks in Natick, Massachusetts, can be purchased with add-on image analysis tools. Volocity from PerkinElmer is popular. ImageJ from the US National Institutes of Health and Cell Profiler from the Broad Institute in Cambridge, Massachusetts, are both freely available and widely used. Several companies, such as Oko Lab in Ottaviano, Italy, Tokai Hit in Shizuoka-ken, Japan, and WaferGen Biosystems in Fremont,
California, sell environmentally controlled microscope slides or other equipment to control conditions on the microscope stage.

Still, a microscope accessory that solves one problem often creates another, says Schroeder. An incubator that fits to the stage of one microscope may not provide the kind of surface that a particular cell type grows on, or tubing that fits an incubator may not attach to a media pump. A computer program names files with a four-digit code, limiting experiments to less than ten-thousand images. And so on. Each problem is trivial individually, says Schroeder, but collectively they sap researchers' motivation and take up time that could be spent on experiments. Anyone who wants to conduct long-term live-cell experiments needs to be ready to spend a long time tinkering with equipment, he says. But the benefits are repeatedly proving worth the hassle, says Cayouette. "The technique is becoming increasingly userfriendly. More and more people are trying to do these long-term imaging studies."

Temple predicts that the results of such studies will be profound. "We've just forgotten the fourth dimension in so many of these analyses," she says. "Now that we've got time, we can finally start to understand."

Monya Baker is technology editor for Nature and Nature Methods.

Qian, X., Goderie, S. K., Shen, Q., Stern, J. H. \& Temple, S Development 125, 3143-3152 (1998)

2. Cohen, A. R., Gomes, F. L. A. F., Roysam, B. \& Cayouette, M Nature Methods 7, 213-218 (2010).

3. Rieger, M. A., Hoppe, P. S., Smejkal, B. M., Eitelhuber, A. C. \& Schroeder, T. Science 325, 217-218 (2009)

4. Chan, E. M. et al. Nature Biotechnol. 27, 1033-1037 (2009)

5. Carlton, P. M. et al. Proc. Natl Acad. Sci. USA advanced online publication doi:10.1073/pnas.1004037107 (2010) 6. Huth, J. et al. BMC Cell Biol. 11, 24 (2010).

\section{Correction}

The Technology Feature 'The gatekeepers revealed' (Nature 465, 823-826; 2010) stated that the crystal structure for the $\mathrm{A} 2 \mathrm{~A}$ adenosine receptor and similar receptors had been solved using an unmodified protein, but referenced the structure of a protein stabilized with T4 lysozyme. Structures for the unmodified receptors have not been published. 